\title{
Análise microestrutural de misturas cerâmicas de grês porcelanato com adição de chamote de telhas cerâmicas
}

\section{(Microstructural analysis of porcelain stoneware tile mixture with the addition of roof tile residue)}

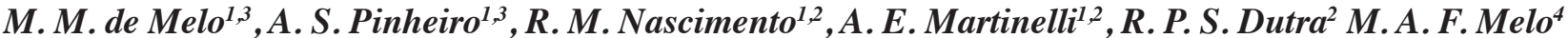 \\ ${ }^{1}$ Programa de Pós-Graduação em Engenharia Mecânica - PPGEM, ${ }^{2}$ Departamento de Engenharia de Materiais \\ - DEMat, ${ }^{3}$ Laboratório de Ensaios de Materiais do CTGÁS/RN, ${ }^{4}$ Programa de Pós-Graduação em Engenharia \\ de Materiais - PPGCEM \\ Universidade Federal do Rio Grande do Norte - UFRN, Campus Universitário - \\ Lagoa Nova, Natal, RN 59072-970
}

\begin{abstract}
Resumo
A necessidade de reutilizar e reciclar rejeitos e resíduos tem exigido das indústrias cerâmicas novas posturas diante do processo de fabricação e seleção de suas matérias-primas. A indústria de telhas de cerâmica vermelha, apesar de constante progresso, ainda não consegue evitar a grande produção de rejeitos oriundos de processamento deficiente de seus produtos, principalmente na etapa de queima. Produtos superqueimados, trincados, quebrados, sem uniformidade de geometria ou de cores, muitas vezes são descartados em aterros, causando prejuízo ambiental. Além disso, há o desperdício de energia, matéria-prima e mão-de-obra, utilizadas na fabricação de produtos não comercializáveis. Em muitas empresas, tais produtos chegam a representar cerca de $20 \%$ de sua produção mensal. Os produtos descartados podem ser reutilizados na produção de cerâmicas, inclusive com maior valor agregado, como grês porcelanato, desde que se conheça seu comportamento quando adicionado à massas cerâmicas. $\mathrm{O}$ presente trabalho tem como objetivo estudar o desenvolvimento microestrutural de massas para grês porcelanato contendo rejeitos de telhas, ou chamote. Foram selecionadas duas formulações conhecidas, uma para grês porcelanato e outra para grês, e adicionados teores de chamote de $10 \%, 20 \%$ e $30 \%$. Três temperaturas de queima foram estudadas, $1150{ }^{\circ} \mathrm{C}, 1200{ }^{\circ} \mathrm{C}$ e $1250^{\circ} \mathrm{C}$ com taxa de aquecimento de $10^{\circ} \mathrm{C} / \mathrm{min}$. Amostras sinterizadas com e sem chamote foram avaliadas quanto à sua microestrutura, absorção de água e porosidade aparente. Tanto a massa para grês porcelanato como para grês tiveram absorção de água reduzida coma adição de chamote. A massa para grês com adição de $30 \%$ de chamore e queimada a $1250^{\circ} \mathrm{C}$ passou a ser considerada grês porcelanato, por ter apresentado absorção de água inferior a $0,5 \%$. O chamote por sua composição mineralógica pode auxiliar na redução da quantidade de matérias-primas fundentes tradicionais, como feldspato e talco, exigidas na fabricação de grês porcelanato.
\end{abstract}

Palavras-chave: grês porcelanato, rejeito de telha, microestrutura.

Abstract

Aiming at reducing environmental impacts, ceramic industries have worked towards adapting their production methods as well as looking into reusing and recycling their own products. The roof tile industry, despite constant development, still produces large volumes of rejected material, as a consequence of faulty processing, especially during firing. Units depicting signs of overfiring, cracking and distortion, as well as geometry and colour non-uniformities are often discarded with no environmental concern. In addition to that, discarded products have negative economic effects considering the energy, raw materials and working hours used in the fabrication of products that do not go to market. Often, defective roof tiles account for $20 \%$ of the monthly production of the ceramic industries. On the other hand, such discarded roof tiles can be reused in the production of new ceramic products, including those with higher added value, such as stoneware tiles. To that end, it is essential to assess the effect of the addition of these ceramic residues in the ceramic mixtures traditionally used to produce stoneware tiles. The present study aimed at investigating the microstructural development of stoneware tile mixtures containing roof tile residues. Contents of 10\%, 20\% and 30\% of residue were added to two different ceramic mixtures. Three firing temperatures were studied, i.e., $1150{ }^{\circ} \mathrm{C}, 1200{ }^{\circ} \mathrm{C}$ and $1250{ }^{\circ} \mathrm{C}$. The heating rate was set to $10{ }^{\circ} \mathrm{C} / \mathrm{min}$. Samples with or without residue were sintered and had their microstructure, water absorption and apparent porosity characterized. The addition of tile roof residue reduced the water absorption of both mixtures studied. By adding $30 \%$ residue to mixture 2 and firing at $1250{ }^{\circ} \mathrm{C}$, it was possible to reduce its water absorption below $0,5 \%$, typical of stoneware tiles. Due to its mineralogical composition, the residue studied can be useful in reducing the large amounts of traditional melting agents, such as feldspar and talc, demanded in the fabrication of stoneware tiles.

Keywords: stoneware tile, roof tile residue, microstructure.

\section{INTRODUÇÃO}

As matérias-primas utilizadas na formulação de massas cerâmicas para fabricação de grês porcelanato possuem características mineralógicas distintas fazendo com que exerçam funções próprias e específicas. As matérias-primas 
argilosas conferem, além de outras propriedades, plasticidade à massa, enquanto as matérias-primas complementares, normalmente não-plásticas, caracterizadas por minerais fundentes ou predominantemente refratários, são responsáveis, principalmente, pela densificação e resistência mecânica do material cerâmico após queima. Além de conferir plasticidade, o caulim é fundamental do ponto de vista composicional, pois aumenta o teor de alumina do grês e auxilia na alvura dos produtos. Os minerais fundentes são representados por feldspatos ou feldspatóides, talco e outras matérias-primas. As matérias-primas refratárias com função estrutural são os quartzos e os quartzitos [1, 2]. As matérias-primas fundentes têm como função básica acelerar a cinética de sinterização por meio da formação de fase líquida viscosa, de modo a adequar as características finais do produto (porosidade, retração linear e resistência mecânica) a um ciclo de queima ideal [3]. Os feldspatos são os principais responsáveis pelas características finais do grês porcelanato. $\mathrm{O}$ tipo de feldspato mais utilizado para sua fabricação é o ortoclásio, rico em potássio. A albita, rica em sódio, é utilizada em menores proporções, para evitar grandes deformações no produto durante a sinterização [3].

$\mathrm{Na}$ etapa de queima, as matérias-primas que contêm minerais alcalinos produzem grande quantidade de fase líquida, cuja viscosidade diminui com o aumento da temperatura. Com isto, ela penetra nos poros existentes, que assim são progressivamente fechados por forças de natureza capilar. Para as temperaturas de sinterização típicas de grês-porcelanato, ou seja, acima de $1050{ }^{\circ} \mathrm{C}$, o quartzo se dissolve parcialmente na fase líquida formando uma nova fase cristalina, a mulita. Assim, o produto queimado é constituído de uma matriz vítrea, na qual partículas de mulita e as partículas de quartzo que não se dissolveram totalmente estão dispersas. Dependendo das características das matérias-primas, assim como da relação argila/feldspato (ingredientes majoritários da composição), a intensidade das transformações físico-químicas aqui descritas pode variar de forma considerável, o que acarretará em diferenças significativas nas propriedades do produto final [4].

Nas últimas décadas, as indústrias têm se deparado com a necessidade de introduzir em seus projetos considerações ecológicas que estejam em conformidade com normas internacionais de proteção ao meio ambiente. Neste sentido, esforços estão sendo concentrados em projetos que visem à redução do volume de rejeitos industriais ou o reaproveitamento destes para a produção de materiais com aplicação comercial [5]. Neste sentido, o presente trabalho tem como objetivo principal estudar a o desenvolvimento microestrutural de materiais cerâmicos classificados como grês porcelanato, obtidos a partir de formulações cerâmicas utilizando matérias-primas tradicionais e resíduo de telhas cerâmicas. Estes resíduos são oriundos da queima irregular desse produto. Em função de sua composição inicial e de queima incompleta, esses resíduos podem apresentar, ainda, características fundentes e possibilidade de aplicação industrial.

\section{MATERIAIS E MÉTODOS}

Para o estudo da evolução microestrutural e análise de fases com a introdução de resíduo de telhas em formulações cerâmicas para produção de grês porcelanato, utilizou-se como matéria-prima uma argila caulinítica com elevada quantidade de óxido de alumínio, caulim, feldspato potássico, talco e resíduo de telhas cerâmicas vermelhas, denominado chamote, proveniente de uma indústria de cerâmica vermelha da região produtora do Vale do Açú, estado do Rio Grande do Norte.

As massas cerâmicas utilizadas para o presente estudo foram elaboradas a partir de duas formulações de massas para grês previamente testadas [6]. Foram adicionados teores de $10 \%, 20 \%$ e $30 \%$ em peso de chamote às misturas. As formulações testadas estão apresentadas na Tabela I. A formulação básica da massa 1 (M1) é composta por matériasprimas, incluindo o talco, utilizadas para a produção de porcelanato, enquanto a formulação básica da massa 2 (M2) é uma formulação que contém, em relação a M1, maiores teores de argila e caulim, menor teor de feldspato e ausência de talco. Essa formulação é típica na fabricação de grês.

Na preparação dos corpos-de-prova a partir das misturas das matérias-primas, utilizou-se uma matriz retangular com punções inferior e superior. A largura, altura e comprimento dos corpos-de-prova obtidos foram $10 \mathrm{~mm}$ x $10 \mathrm{~mm}$ x 100 $\mathrm{mm}$. A pressão de compactação utilizada foi $45 \mathrm{MPa}$. Para a dosagem das massas foi utilizada uma balança analítica com precisão de $0,0002 \mathrm{~g}$, adicionando-se $10 \%$ de teor de água. Após a obtenção dos corpos-de-prova, estes foram submetidos à secagem em estufa, em temperatura controlada $\left(110{ }^{\circ} \mathrm{C}\right)$, até obter-se massa constante. Em seguida, os corpos-de-prova secos foram medidos com paquímetro com resolução de $0,05 \mathrm{~mm}$. A queima dos corpos-de-prova foi realizada em um forno a gás natural Grion. Três temperaturas de queima foram estudadas: $1150{ }^{\circ} \mathrm{C}, 1200^{\circ} \mathrm{C}$ e $1250{ }^{\circ} \mathrm{C}$. A taxa de aquecimento foi de $10^{\circ} \mathrm{C} / \mathrm{min}$. Em cada queima, o

Tabela I - Misturas cerâmicas estudadas.

[Table I - Porcelain stoneware mixtures]

\begin{tabular}{cccccc}
\hline \multirow{2}{*}{ Mistura } & \multicolumn{5}{c}{$\%$ em peso } \\
\cline { 2 - 6 } & Argila & Feldspato & Caulim & Talco & Chamote \\
\hline \multicolumn{5}{c}{ Massa 1 - M1 } \\
\hline M1 & 35,0 & 45,0 & 17,0 & 3,0 & - \\
M1-10 & 31,5 & 40,5 & 15,3 & 2,7 & 10 \\
M1-20 & 28,0 & 36,0 & 13,6 & 2,4 & 20 \\
M1-30 & 24,5 & 31,5 & 11,9 & 2,1 & 30 \\
\hline \multicolumn{7}{c}{ Massa 2 - M2 } \\
\hline M2 & 40,0 & 40,0 & 20,0 & - & - \\
M2-10 & 36,0 & 36,0 & 18,0 & - & 10 \\
M2-20 & 32,0 & 32,0 & 16,0 & - & 20 \\
M2-30 & 28,0 & 28,0 & 14,0 & - & 30 \\
\hline
\end{tabular}


patamar na temperatura máxima foi $30 \mathrm{~min}$. O resfriamento ocorreu de forma natural, com as amostras dentro do forno desligado, até que a temperatura ambiente fosse atingida.

Para avaliar as propriedades finais de cada produto, foram realizadas análises para identificação de fases cristalinas por difração de raios $\mathrm{X}$ (DRX), porosidade aparente (PA), absorção de água (AA) e análise microestrutural por microscopia eletrônica de varredura (MEV). $\mathrm{Na}$ determinação da porosidade aparente e absorção de água foram utilizados os corpos-de-prova nas mesmas dimensões após a etapa de queima. A microscopia eletrônica de varredura foi utilizada com o objetivo principal de avaliar as eventuais transformações de fases, bem como identificação da porosidade presente nos corpos-de-prova. Este ensaio foi realizado para cada conjunto de amostras. Em seguida, cada amostra foi fraturada para ser analisada de duas formas: análise da microestrutura externa, objetivando avaliar,

Q- Quartzo C-Caulinita F-M croclínio A-Albita H-Haloisita T-Talco M-Mulita

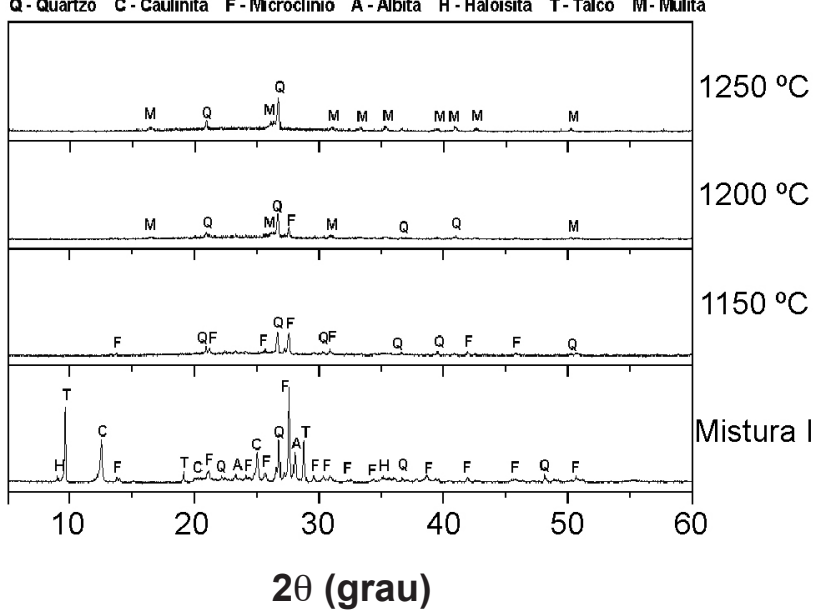

(a)

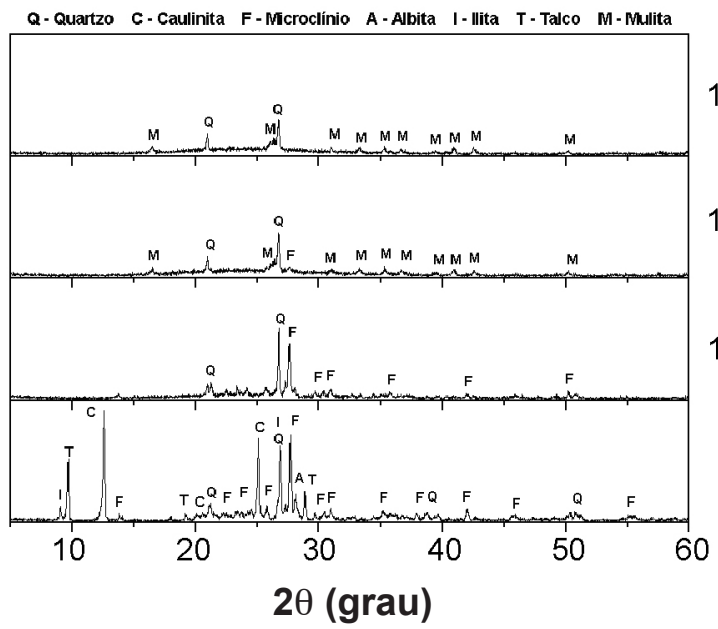

(c)

12 principalmente, a porosidade aberta e a textura do material; e análise da microestrutura interna, visando avaliar as fases formadas, bem como a porosidade fechada. Do ponto de vista das fases formadas, as amostras foram observadas após ataque da superfície de fratura com ácido fluorídrico (HF) a $2 \%$ em água destilada.

\section{RESULTADOS E DISCUSSÃO}

A Fig. 1 apresenta os resultados das análises de fases obtidas por difração de raios $\mathrm{X}$ das amostras confeccionadas a partir da mistura 1 (M1). As Figs. 1a-d apresentam comparações de cada mistura, a verde e após sinterização em diferentes temperaturas, $1150{ }^{\circ} \mathrm{C}, 1200{ }^{\circ} \mathrm{C}$ e $1250{ }^{\circ} \mathrm{C}$. Todas as amostras, quando queimadas a partir de $1200{ }^{\circ} \mathrm{C}$, apresentam a formação de mulita $\left(3 \mathrm{Al}_{2} \mathrm{O}_{3} \cdot 2 \mathrm{SiO}_{2}\right)$. Essa fase é formada a partir de espinélios e aluminossilicatos amorfos

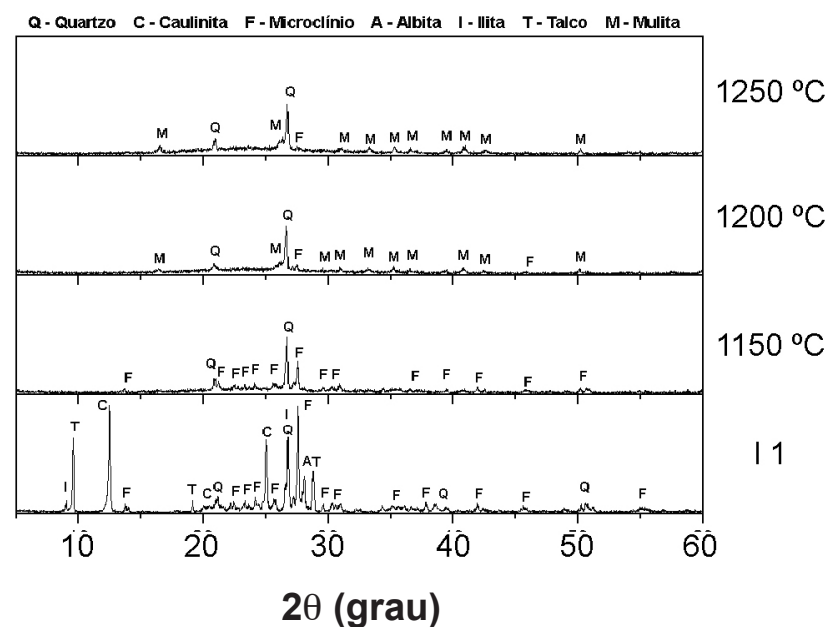

(b)

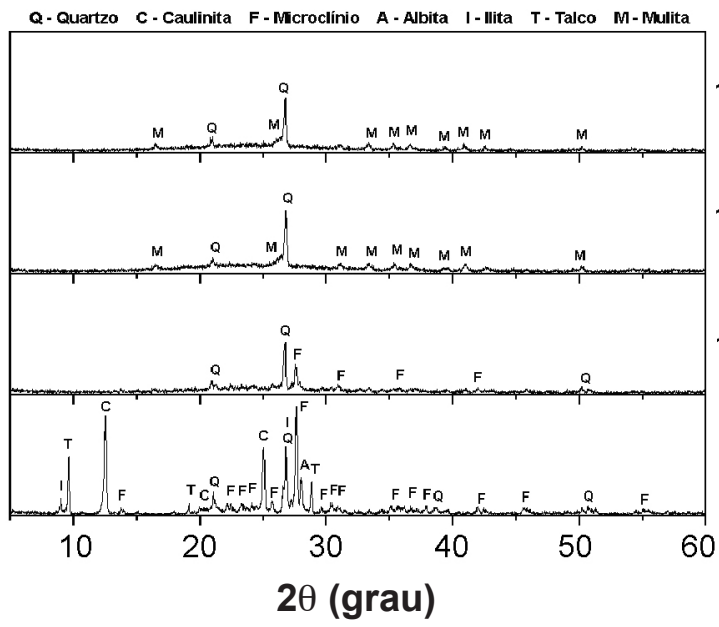

$1250^{\circ} \mathrm{C}$

$1200^{\circ} \mathrm{C}$

$1150^{\circ} \mathrm{C}$

(d)

Figura 1: Difratogramas de raios X da mistura 1 sem (a) e com adição de chamote (b-10\%, c-20\% e d-30\%) em diferentes temperaturas de sinterização.

[Figure 1: X-ray diffraction patterns of mixture 1 without (a) and with roof tile residue (b-10\%, c-20\% and d-30\%) after different sintering temperatures.] 
obtidos a $980{ }^{\circ} \mathrm{C}$, originada das argilas que possuem como minerais argilosos a caulinita e a ilita, além de outros aluminosilicatos. Observa-se, também, a partir da primeira queima $\left(1150{ }^{\circ} \mathrm{C}\right)$ o afastamento da linha de base dos difratogramas em relação ao eixo da abscissa, principalmente entre $15^{\circ}$ e $35^{\circ}$, enquanto que alguns picos deixam de existir. Este comportamento indica uma maior quantidade de fase vítrea, gerada pela dissolução dos metais alcalinos presentes nas matérias-primas que compõem as misturas.

Observa-se ainda na Fig. 1 que a amostra sem rejeito apresentou menor quantidade de quartzo, quando queimada, seja a $1150{ }^{\circ} \mathrm{C}, 1200^{\circ} \mathrm{C}$ ou $1250^{\circ} \mathrm{C}$, com relação às amostras com adição de chamote. A diferença entre a amostra a verde para a obtida a partir da primeira queima $\left(1150{ }^{\circ} \mathrm{C}\right)$, em qualquer uma das formulações, é que somente as fases quartzo e feldspato continuam presentes. Pode-se observar também que entre a amostra sem chamote e a com $10 \%$, o feldspato não se dissolve totalmente para a mistura com chamote na temperatura de $1250{ }^{\circ} \mathrm{C}$. Isso indica que a adição de $10 \%$ do resíduo de telha na formulação 1 ocasiona, provavelmente, um atraso na fusão do feldspato. Outro fenômeno que se verificar entre as amostras com adição do resíduo é que à medida que o teor de chamote aumentou de $10 \%$ a $30 \%$, a presença do feldspato diminui a temperaturas de sinterização cada vez mais baixas. Com $10 \%$ de resíduo de telha, encontrou-se feldspato após a queima de $1250{ }^{\circ} \mathrm{C}$. Já para a concentração de $20 \%$, não se encontrou feldspato após a queima nessa mesma temperatura, mas somente a $1200{ }^{\circ} \mathrm{C}$. Por fim, percebe-se também, que para $30 \%$ de chamote, só se identifica feldspato após a queima de $1150{ }^{\circ} \mathrm{C}$.

A Fig. 2 apresenta os difratogramas para as formulações geradas a partir da massa 2 (M2). A presença de chamote não provocou mudanças significativas na transformação das fases do material queimado, independente da temperatura e do teor

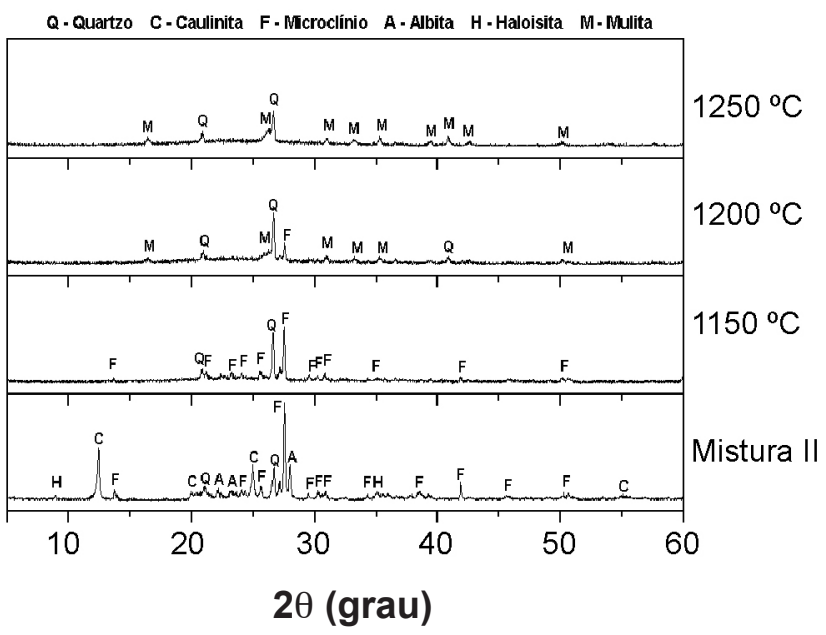

(a)

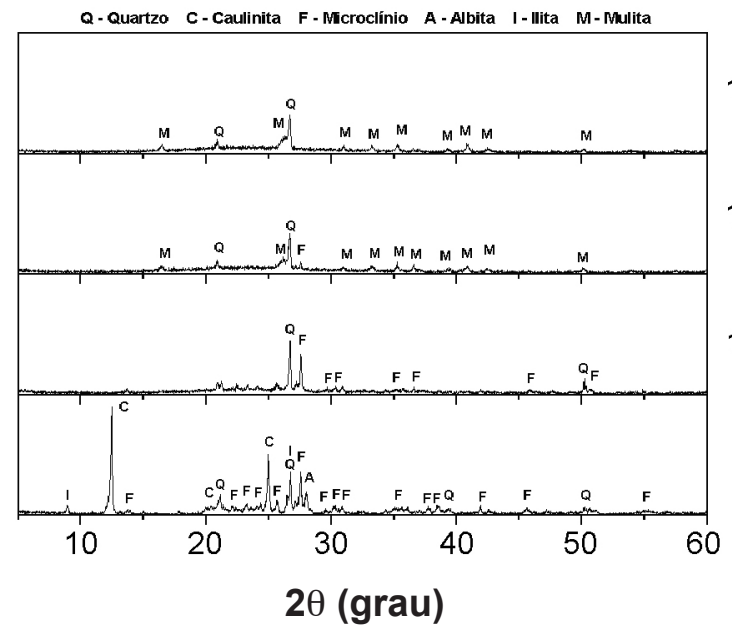

(c)

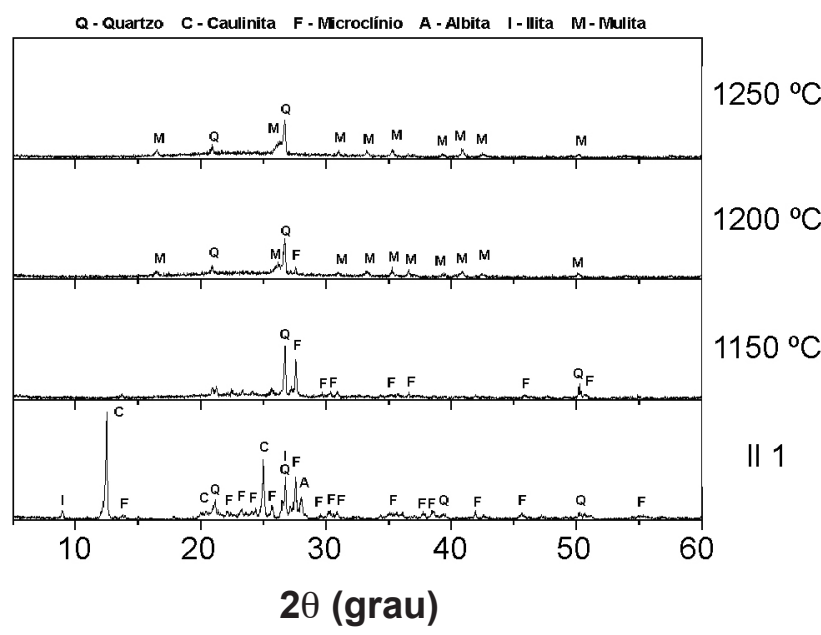

(b)

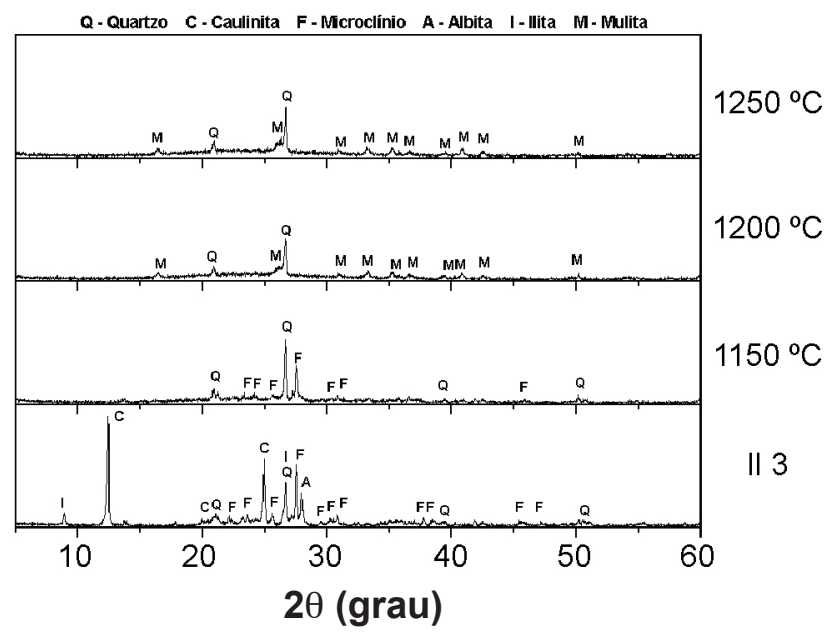

(d)

Figura 2: Difratogramas de raios X da mistura 2 sem (a) e com adição de chamote (b-10\%, c-20\% e d-30 \%) em diferentes temperaturas de sinterização.

[Figure 2: X-ray diffraction patterns of mixture 2 without (a) and with roof tile residue (b-10\%, c-20\% and d-30\%) after different sintering temperatures.] 
de rejeitos. Contudo, à medida que o chamote é adicionado à formulação 2 , o feldspato se dissolve cada vez mais em temperaturas mais baixas, como é possível notar na Fig. 2a sem adição de rejeito. $\mathrm{O}$ feldspato está presente no material queimado a $1200{ }^{\circ} \mathrm{C}$, para a massa 2 sem adição de chamote e com adição de 10 e $20 \%$ de chamote. No primeiro caso, sua presença é mais acentuada. Isto leva a crer que a presença de chamote ajuda a diminuir o ponto de fusão do feldspato, podendo com isso, reduzir a temperatura de sinterização. Este comportamento é observado mais facilmente quando a adição é de $30 \%$ de resíduo, constatando-se que o feldspato só aparece até a temperatura de $1150{ }^{\circ} \mathrm{C}$.

A Tabela II apresenta os resultados da porosidade aparente para as amostras sinterizadas a partir das massas sem e com adição de chamote. Os valores de porosidade aparente para as massas com adição de chamote encontram-se todos abaixo de $0,5 \%$, independentes do teor e da temperatura de queima.

Para as amostras sinterizadas da mistura 1 com adição de chamote, embora os valores da porosidade aparente estejam bem próximos para cada temperatura de queima, o teor de chamote influencia a porosidade aparente, exceto para a queima a $1250{ }^{\circ} \mathrm{C}$. Para $1150{ }^{\circ} \mathrm{C}$, os valores da porosidade aparente são $0,29 \%, 0,28 \%$ e $0,26 \%$, para os teores de $10 \%$, $20 \%$ e $30 \%$ de chamote, respectivamente. Para $1200{ }^{\circ} \mathrm{C}$, os valores de porosidade medidos foram $0,07 \%, 0,05 \%$ e $0,03 \%$. Para a temperatura máxima de queima de $1250{ }^{\circ} \mathrm{C}$, não houve variação da porosidade em função dos diferentes teores de chamote. De acordo com a Tabela II, é possível perceber que o teor de adição de chamote à massa 2 influenciou a porosidade aparente de forma mais marcante do que para a mistura 1 . Observa-se que para $1150{ }^{\circ} \mathrm{C}$, foram medidos valores de porosidade iguais a $0,32 \%, 0,30 \%$ e $0,29 \%$ para os teores de $10 \%, 20 \%$ e $30 \%$ de chamote, respectivamente. Para $1200{ }^{\circ} \mathrm{C}$, os valores encontrados foram $0,11 \%, 0,09 \%$ e $0,06 \%$, também para os teores de $10 \%, 20 \%$ e $30 \%$. Para a temperatura máxima de queima, $1250{ }^{\circ} \mathrm{C}$, a variação também foi pequena em função de diferentes concentrações de chamote. Os valores de porosidade para os teores de $10 \%, 20 \%$ e $30 \%$ de chamote foram $0,03 \%, 0,02 \%$ e $0,01 \%$, respectivamente.

A Tabela III apresenta os resultados de absorção de água para as amostras sinterizadas a partir das 2 misturas sem e com adição de chamote. Para cada formulação, os valores de absorção de água diminuem à medida que a temperatura de queima aumenta. Observa-se que há grande diferença no valor da absorção (praticamente o dobro) entre as amostras da mistura 1 sem chamote, 16,81\%, em comparação com as amostras com adição de chamote (I1, I2 e I3), entre 8,35 e $8,42 \%$, queimados a $1150^{\circ} \mathrm{C}$. Para a temperatura de queima de $1200{ }^{\circ} \mathrm{C}$, nota-se facilmente que à medida que o chamote é incorporado na formulação do corpo-de-prova, sua absorção de água diminui. Já a $1250{ }^{\circ} \mathrm{C}$, observa-se uma nova reaproximação dos valores de absorção de água de todas as formulações, incluindo a formulação de partida. Os corpos-de-prova da massa de partida apresentaram valor acima $(0,67 \%)$ do limite máximo de absorção de água para um grês porcelanato, que é de $0,5 \%$. Contudo, as amostras com adição de chamote apresentaram valores de absorção de água abaixo do limite máximo. I- $10=0,46 \%$; I- $20=0,26 \%$; e I-30 $=0,20 \%$. Com tais valores, ainda que próximos uns dos outros, consegue-se observar que para a temperatura de queima de $1250{ }^{\circ} \mathrm{C}$, a quantidade de chamote influencia na absorção de água, ou seja, quanto mais chamote (entre $10 \mathrm{e}$ $30 \%$ de adição), menor a absorção de água.

Já para a mistura 2, quanto maior o teor de chamote, menor foi a absorção de água. Assim, a mistura 2 sem adição de chamote e com adição de $10 \%$ e $20 \%$ apresentou percentuais de absorção de água de 2,03\%, 1,41\% e 0,77\%, respectivamente. Esses valores estão acima do limite máximo admitido para um grês porcelanato que é $0,5 \%$. Contudo, as amostras com adição de $30 \%$ de chamote apresentaram valores de absorção de água abaixo desse limite.

A Fig. 3 apresenta micrografias MEV da superfície de

Tabela II - Porosidade aparente das amostras das misturas 1 e 2 sem e com a adição de chamote nas proporções de 10,20 e $30 \%$ queimadas a 1150,1200 e $1250{ }^{\circ} \mathrm{C}$.

[Table II - Apparent porosity of formulation 1 and 2 samples, without and with the addition of $10 \%, 20 \%$ and $30 \%$ residue. Firing temperature: 1150,1200 and $1250{ }^{\circ} \mathrm{C}$.]

\begin{tabular}{rcccc}
\hline \multirow{2}{*}{ Temperatura } & \multicolumn{4}{c}{ Porosidade aparente, $(\%)$} \\
\cline { 2 - 5 } & M1 & M1-10 & M1-20 & M1-30 \\
\hline $1150{ }^{\circ} \mathrm{C}$ & $30,25 \pm 2,34$ & $0,29 \pm 0,01$ & $0,28 \pm 0,02$ & $0,26 \pm 0,03$ \\
$1200^{\circ} \mathrm{C}$ & $9,80 \pm 2,24$ & $0,07 \pm 0,01$ & $0,05 \pm 0,01$ & $0,03 \pm 0,01$ \\
$1250{ }^{\circ} \mathrm{C}$ & $1,57 \pm 0,31$ & $0,01 \pm 0,00$ & $0,01 \pm 0,00$ & $0,01 \pm 0,00$ \\
\hline & $\mathrm{M} 2$ & M2-10 & M2-20 & M2-30 \\
\hline $1150{ }^{\circ} \mathrm{C}$ & $31,80 \pm 2,34$ & $0,32 \pm 0,02$ & $0,30 \pm 0,01$ & $0,29 \pm 0,04$ \\
$1200{ }^{\circ} \mathrm{C}$ & $14,28 \pm 1,97$ & $0,11 \pm 0,02$ & $0,09 \pm 0,01$ & $0,06 \pm 0,01$ \\
$1250{ }^{\circ} \mathrm{C}$ & $4,76 \pm 1,07$ & $0,03 \pm 0,00$ & $0,02 \pm 0,01$ & $0,01 \pm 0,01$ \\
\hline
\end{tabular}


Tabela III - Absorção de água das amostras das misturas 1 e 2 sem e com adição de chamote nas proporções de 10,20 e $30 \%$ queimadas a 1150,1200 e $1250{ }^{\circ} \mathrm{C}$.

[Table III - Water absorption of formulation 1 and 2 samples, without and with addition of $10 \%, 20 \%$ and $30 \%$ residue. Firing temperature: 1150,1200 and $1250{ }^{\circ} \mathrm{C}$.]

\begin{tabular}{rcccc}
\hline \multirow{2}{*}{ Temperatura } & \multicolumn{4}{c}{ Absorção de água (\%) } \\
\cline { 2 - 5 } & M1 & M1-10 & M1-20 & M1-30 \\
\hline $1150{ }^{\circ} \mathrm{C}$ & $16,81 \pm 1,88$ & $8,35 \pm 0,57$ & $8,38 \pm 1,55$ & $8,42 \pm 2,10$ \\
$1200{ }^{\circ} \mathrm{C}$ & $4,41 \pm 1,53$ & $3,14 \pm 0,46$ & $1,92 \pm 0,42$ & $1,33 \pm 0,48$ \\
$1250{ }^{\circ} \mathrm{C}$ & $0,67 \pm 0,14$ & $0,46 \pm 0,10$ & $0,26 \pm 0,06$ & $0,20 \pm 0,06$ \\
\hline & $\mathrm{M} 2$ & $\mathrm{M} 2-10$ & $\mathrm{M} 2-20$ & $\mathrm{M} 2-30$ \\
\hline $1150{ }^{\circ} \mathrm{C}$ & $18,03 \pm 1,96$ & $16,78 \pm 0,35$ & $16,40 \pm 0,75$ & $14,68 \pm 1,01$ \\
$1200{ }^{\circ} \mathrm{C}$ & $6,52 \pm 2,30$ & $4,90 \pm 0,91$ & $4,08 \pm 0,56$ & $2,50 \pm 0,67$ \\
$1250{ }^{\circ} \mathrm{C}$ & $2,03 \pm 0,49$ & $1,41 \pm 0,17$ & $0,77 \pm 0,27$ & $0,48 \pm 0,23$ \\
\hline
\end{tabular}
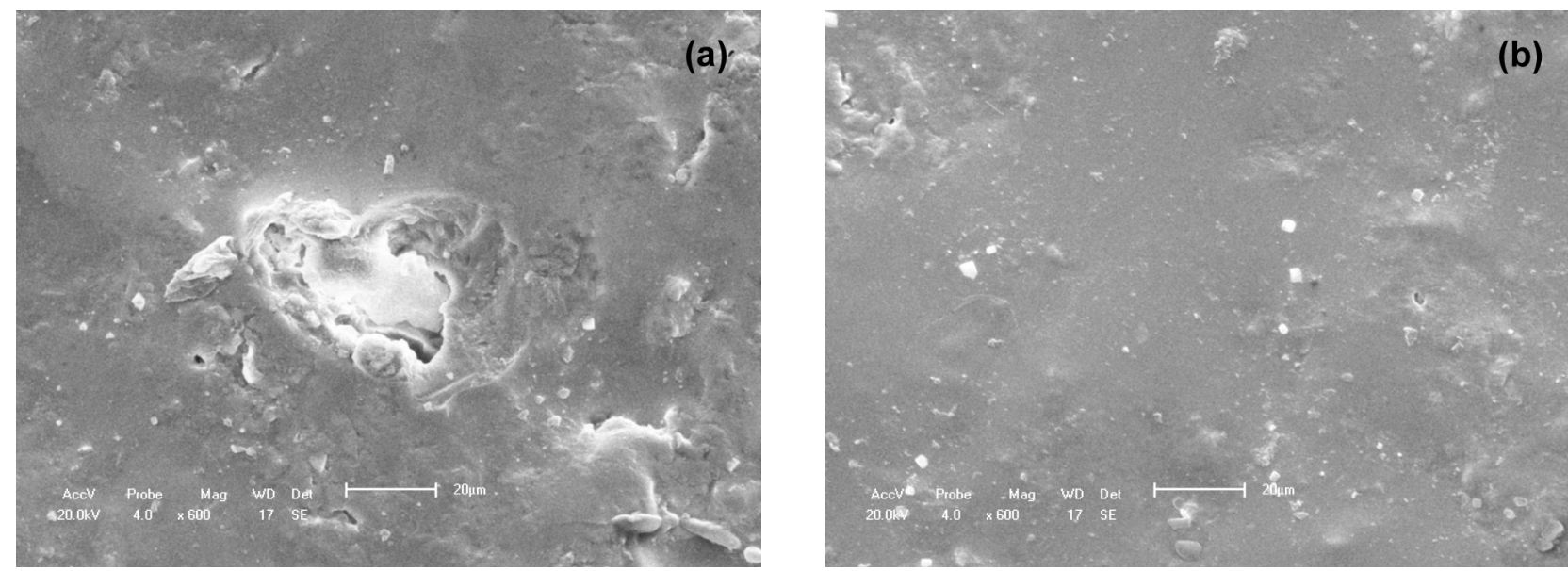

Figura 3: Micrografias obtidas por microscopia eletrônica de varredura da superfície dos corpos-de-prova da mistura 1 sinterizada a $1250{ }^{\circ} \mathrm{C}$ : (a) sem adição de chamote e (b) com adição de $30 \%$ de chamote.

[Figure 3: Electronic images of the surface of mixture 1 samples fired at $1250{ }^{\circ} \mathrm{C}:$ (a) without residue and (b) with $30 \%$ residue.]

amostras obtidas a partir da sinterização da mistura 1 sem chamote e com adição de $30 \%$ de chamote. A amostra sem chamote apresentou superfície com maior rugosidade do que a amostra com $30 \%$ de chamote. Este comportamento deve-se, provavelmente, ao fato de a amostra com rejeito apresentar maior teor de fundentes, o que proporciona maior conteúdo de fase líquida durante o processo de sinterização e, portanto menor rugosidade final. Observou-se, ainda, que a amostra sem adição de chamote apresenta porosidade aberta, ao contrário da amostra com $30 \%$ de rejeito.

A Fig. 4 apresenta micrografias eletrônicas da superfície de fratura de corpos-de-prova da mistura 1 sem chamote e com adição de $30 \%$ de chamote. Três regiões diferentes são destacadas nessas imagens. A região A é característica de áreas pouco sinterizadas. A região B mostra a presença de fase vítrea solidificada, enquanto a região $\mathrm{C}$ ilustra poros fechados no corpos-de-prova. A superfície de fratura da amostra sem adição de chamote apresentou regiões com menor quantidade de fase vítrea solidificada, quando comparada à amostra com adição de $30 \%$ de chamote. Já com relação à porosidade fechada, observa-se um comportamento inverso. A amostra sem chamote apresentou menor porosidade fechada do que a amostra com 30\% de chamote. Essa diferença também está relacionada a maior quantidade de fundentes da amostra com chamote, o que provoca a liberação de mais gases provenientes da decomposição de inclusões ricas em voláteis, ocasionando a formação de maior porosidade fechada. A ausência de poros abertos impede a saída de gases das regiões mais internas da amostra durante o processo de queima a altas temperaturas [7].

A Fig. 5 apresenta a superfície externa de amostras obtidas a partir da mistura 2 sem e com adição de $30 \%$ chamote. A amostra sem adição de rejeito (Fig. 5a) possui porosidade aberta maior que a amostra com $30 \%$ de chamote (Fig. 5b), o que comprova a maior absorção de água da mistura 2 sem adição de chamote.

A Fig. 6 apresenta micrografias eletrônicas características 

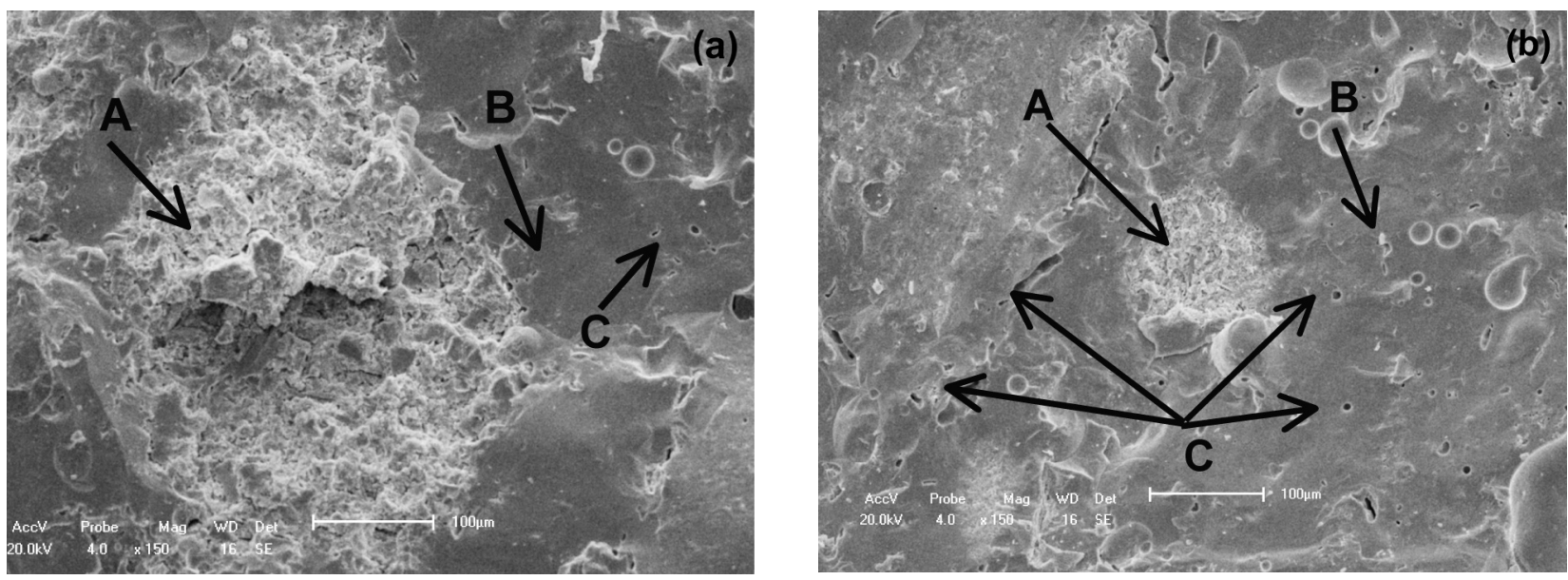

Figura 4: Micrografias obtidas por microscopia eletrônica de varredura da superfície de fratura de amostras da mistura 1 sinterizadas a $1250{ }^{\circ} \mathrm{C}$ : (a) sem adição de chamote, (b) com adição de $30 \%$ de chamote.

[Figure 4: SEM images of the fracture surface of mixture 1 samples fired at $1250{ }^{\circ} \mathrm{C}:(a)$ without residue and (b) with $30 \%$ residue.]
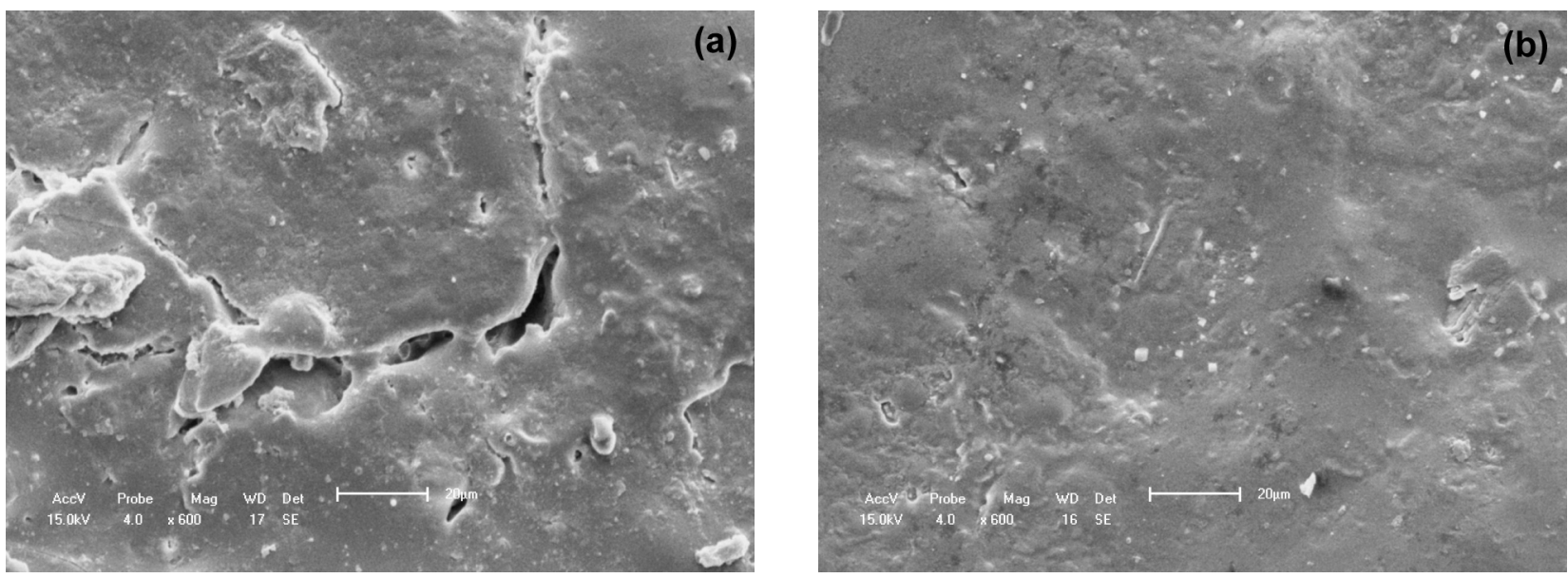

Figura 5: Micrografias obtidas por microscopia eletrônica de varredura da superfície externa dos corpos-de-prova da M2 sinterizadas a $1250{ }^{\circ} \mathrm{C}$ : (a) sem adição de chamote, (b) com adição de $30 \%$ de chamote.

[Figure 5: SEM images of the surface of mixture 2 samples fired at $1250{ }^{\circ} \mathrm{C}:$ (a) without residue and (b) with $30 \%$ residue.]
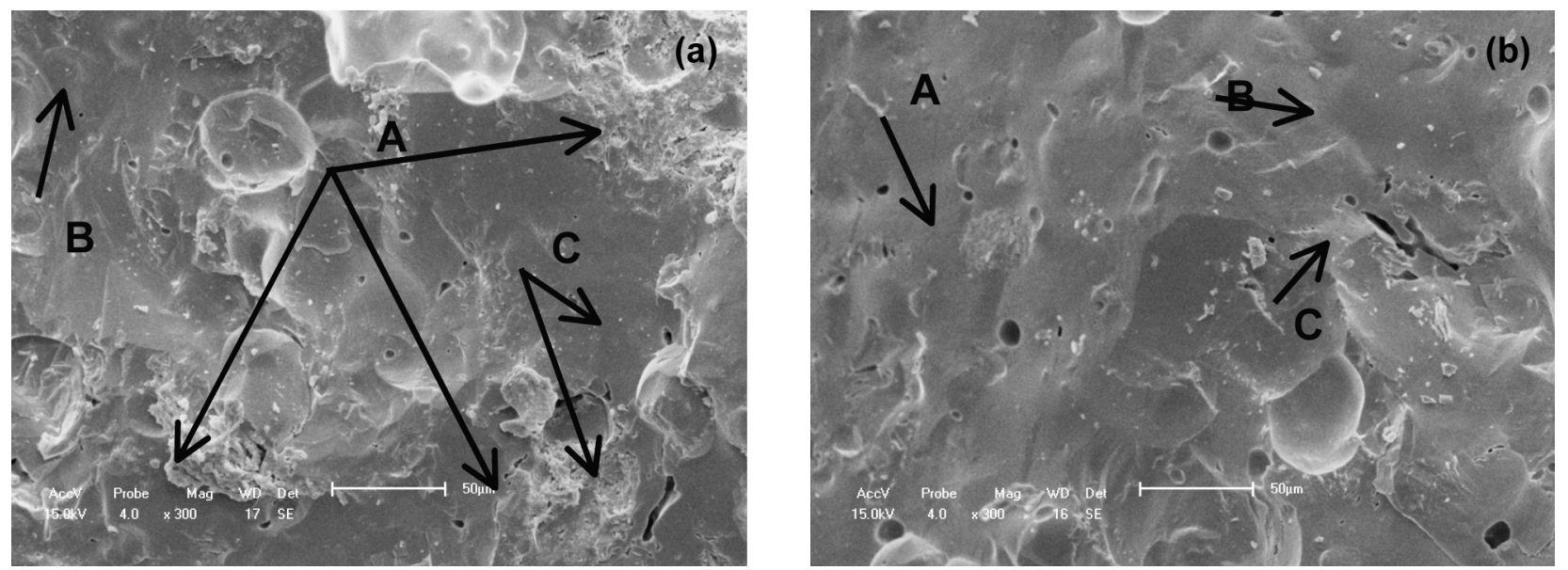

Figura 6: Micrografias obtidas por microscopia eletrônica de varredura da superfície de fratura de amostras da mistura 2 sinterizadas a $1250{ }^{\circ} \mathrm{C}$ : (a) sem adição de chamote, (b) com adição de $30 \%$ de chamote.

[Figure 6: SEM images of the fracture surface of mixture 2 samples fired at $1250^{\circ} \mathrm{C}:$ (a) without residue and (b) with $30 \%$ residue.] 

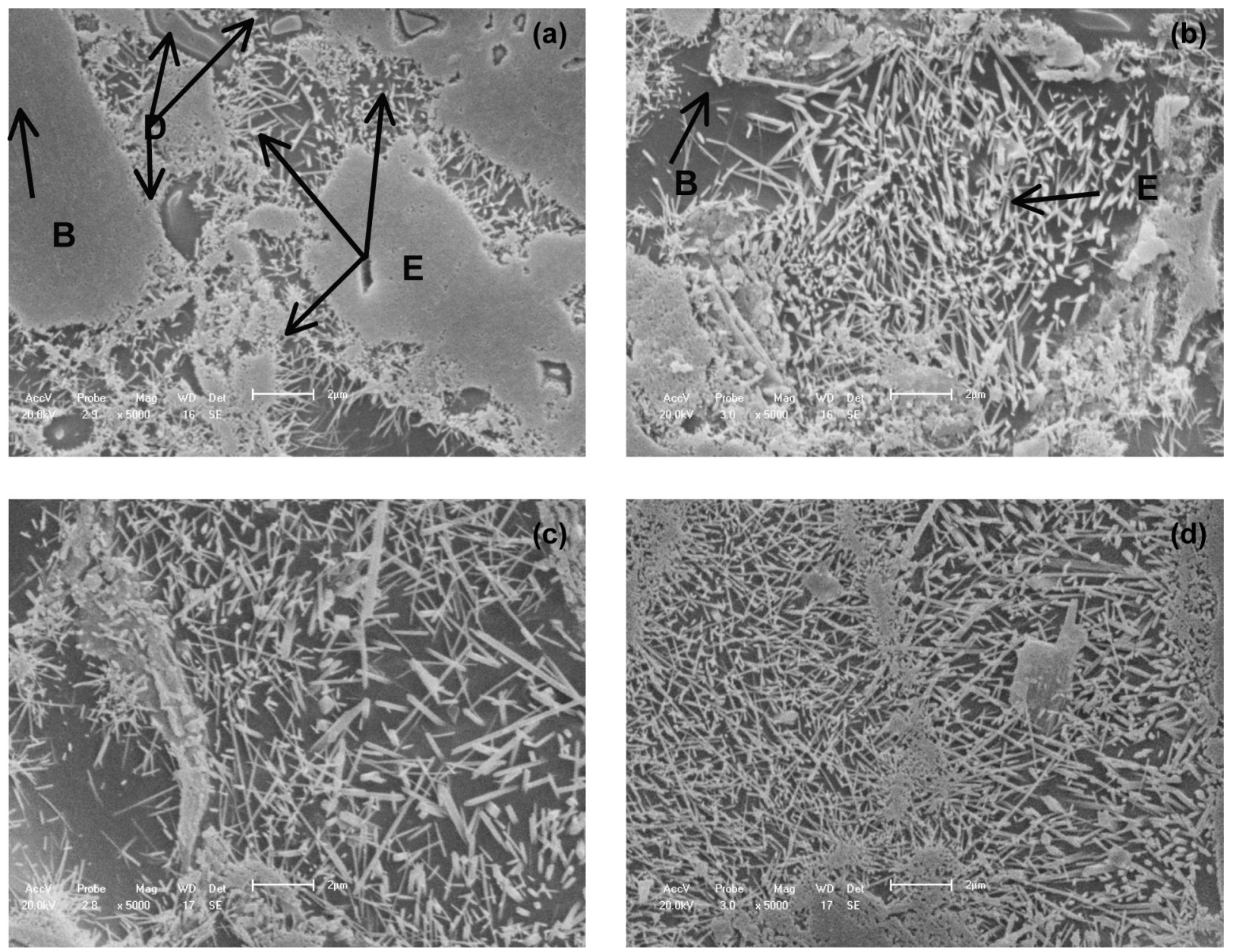

Figura 7: Micrografias obtidas por microscopia eletrônica de varredura da superfície de fratura de amostras com adição de $30 \%$ de chamote sinterizadas a $1200{ }^{\circ} \mathrm{C}$ : (a) mistura 1, (b) mistura 2. Sinterizada a $1250{ }^{\circ} \mathrm{C}$ : (c) mistura 1 , (d) mistura 2.

[Figure 7: SEM images of the fracture surface of samples containing $30 \%$ residue fired at $1200{ }^{\circ} \mathrm{C}:$ (a) mixture 1 , (b) mixture 2. Fired at $1250^{\circ} \mathrm{C}:($ c) mixture $1,(d)$ mixture 2 .

da superfície de fratura de amostras da mistura 2 sem e com adição de $30 \%$ chamote. A amostra sem adição de rejeito apresentou maior volume de regiões não vitrificadas. $\mathrm{Na}$ amostra com $30 \%$ de chamote predominou uma superfície de fratura constituída praticamente de fase vítrea.

A Fig. 7 apresenta as superfícies de fratura das amostras atacadas com $\mathrm{HF}$ a $2 \%$ em $\mathrm{H}_{2} \mathrm{O}$, obtidas a partir das misturas 1 e 2, ambas com adição de $30 \%$ de chamote e sinterizadas a 1200 e $1250{ }^{\circ} \mathrm{C}$. É possível observar a partir das Figs. $7 \mathrm{a}$ e $7 \mathrm{~b}$ a presença de grandes concentrações de mulita na forma acicular. Na mistura 1 com 30\% de chamote (Fig. 7a), sinterizada a $1200^{\circ} \mathrm{C}$, verificam-se grãos de quartzo em fase de dissolução (região D), como também uma grande região vitrificada (região B). Observa-se também que a fase vitrificada está presente de forma mais marcante na amostra da mistura 1 em comparação à mistura 2, devido à presença de talco, que possibilita a fusão do feldspato em temperaturas mais baixas. Contudo, observa-se na Fig. $7 \mathrm{~b}$ maior presença de cristais aciculares de mulita (região E). É possível que a maior quantidade de mulita tenha ocorrido em função do maior teor de caulinita na mistura, presente tanto na argila quanto no caulim. Para a sinterização a $1250{ }^{\circ} \mathrm{C}$ (Figs. $7 \mathrm{c}$ e 7d), observa-se que o teor de mulita aumentou em ambas amostras, embora seja possível notar a maior presença desses cristais na amostra da mistura 2 (Fig. 7d).

\section{CONCLUSÕES}

A obtenção de grês porcelanato é possível com adição de até $30 \%$ de chamote a massas cerâmicas padrões contendo argila, caulim e feldspato ou argila, caulim, feldspato e talco. A presença de chamote, bem como a temperatura de sinterização dessas misturas modificam a microestrutura final do material, alterando a natureza e os teores de fases cristalinas e amorfas formadas e a porosidade aparente do material. É possível obter grês porcelanato a partir de uma mistura para grês com absorção de água acima de $0,5 \% \mathrm{com}$ a adição de $30 \%$ de chamote de telha. A adição de chamote em até $30 \%$, tanto na formulação 1 como na formulação 2 , melhora, ainda, as características da camada superficial do material em virtude da maior formação de fase vítrea durante a sinterização. De maneira geral, o trabalho demonstra que o chamote de telhas pode ser considerado matéria-prima cerâmica com grande potencial de utilização como fundente 
na formulação de grês porcelanato, melhorando as qualidades técnicas do material e reduzindo seu custo de produção.

\section{AGRADECIMENTOS}

Ao SENAI/PETROBRAS/CTGAS e à UFRN pelo incentivo à realização desse estudo e permissão de uso de seus laboratórios.

\section{REFERÊNCIAS}

[1] A. P. N. Oliveira, Cerâmica Industrial 3, 1 ( 1998) 34.

[2] A. M. Rodriguez, S. A. Pianaro, E. A. T. Berg, A. H. Santos, Cerâmica Industrial 9, 1(2004) 33.
[3] C. D. G. Borba, J. B. R. Neto, A. P. N. Oliveira, E. C. F. Echude, O. E. Alarcón, Cerâmica Industrial 1, 1 (1996) 34.

[4] E. Sánchez, A. Barba, C. Feliu, J. García, F. Ginés, V. Sanz, V. Beltrán, Materias primas para la fabricación de suportes de baldosas cerámicas, $1^{\text {a }}$ Ed., Instituto de Tecnología Cerámica, Castellón, Espanha (1997) 126.

[5] M. V. Folgueras, J. P. M. Feijão, A. P. Oliveira, O. E. Alarcón, Anais $43^{\circ}$ Cong. Bras. Cerâmica, Florianópolis, SC (1999) cd rom.

[6] A. S. Pinheiro, Produção de grês porcelanato a partir de matérias-primas do Rio Grande do Norte e queima a gás natural, Diss. Mestrado, UFRN (2006) 115p.

[7] L. S. Muñoz, S. S. Cava, C. A. Paskocimas, E. Cerisuelo, E. Longo, J. B. Carda, Cerâmica 48, 308 (2002) 217.

(Rec. 27/11/2008, Ac. 18/12/2008) 